\title{
QUANDO OS JOVENS VIRAM NOTÍCIA DE JORNAL? UMA ANÁLISE DAS REPRESENTAÇÕES SOCIAIS NA MÍDIA
}

Ilana Eleá S. Werneck

Mestranda em Educação, PUC-Rio, Brasil

\section{INTRODUÇÃO}

Estudar a forma como diferentes grupos vem sendo representados pelos meios de comunicação de massa é uma das maneiras de se realizar pesquisas educativas em torno da mídia. As formas através das quais as mídias se ocupam da família, do gênero (masculino/feminino), da relação adulto-criança, das minorias e dos jovens, por exemplo, ajuda os educadores a problematizarem a função dos estereótipos veiculados na estruturação dos quadros de valores e de comportamento desses grupos. Trata-se de um tema importantíssimo no âmbito da pesquisa educativa se pensarmos que estas representações constituem um dos territórios privilegiados da educação informal.

Dentro da categorização realizada por Rivoltella (2001) sobre ações mídia-educativas, a opção pelo estudo das representações sociais está inserida na chamada "proposta ideológica", a qual pretende trazer reflexões aos sujeitos, tendo consciência que "ler criticamente um produto midiático não significa mais aproxima-lo através parâmetros de valor (bonito/feio, bom/mal), mas desconstruí-lo, desmitificar a sua cobertura ideológica, reconhecer os traços da cultura hegemônica” (2001:49)

\section{POR QUE ESTUDAR O JOVEM NO JORNAL?}

Partindo dos pressupostos acima citados, cabe aos educadores atentarem para o potencial formador dos meios de comunicação de massa. Este estudo procura mapear como os jovens têm sido vistos, citados e representados através de um meio de comunicação de massa específico - o jornal. A escolha pelo estudo do jornal $O$ Globo deveu-se por esse se apresentar como um jornal de grande circulação no país. Foram decupadas todas as matérias que tematizavam a juventude num período de 26 dias consecutivos (16 de março a 6 de abril de 2004).

Ao falarmos em juventude, estamos nos referindo ao momento posterior à infância, que envolve a adolescência e a juventude propriamente dita, que aqui adotamos como o período entre os 16 e os 24 anos.

Segundo Abramo (1997) ${ }^{1}$, existe uma distinção entre os modos como são tematizados os jovens nos meios de comunicação: quando os produtos são dirigidos diretamente a este público, os temas normalmente são cultura e comportamento - música, moda, estilo de vida, esporte e lazer; em contrapartida, quando os jovens são assunto de noticiários, matérias analíticas ou editoriais, os temas abordados são de um modo geral,violência, crime, explotação sexual e drogadicção.

\footnotetext{
${ }^{1}$ Abramo, Helena Wendel. Considerações sobre a tematização social da juventude no Brasil. IN: Revista Brasileira de Educação, n.5, p.25-35.
} 
Isso pode ser erificado também nos jornais? Para Barbero $(2001)^{2}$, por mais que a televisão se apresente como o mais "sofisticado dispositivo de moldagem", ela não funciona sozinha, devendo conviver/competir com outras mediações, como os valores instituídos pela família, pela escola, pelos amigos, enfim, pelo meio social em que o indivíduo estiver inserido.

Nesse contexto de mediações, o jornal costuma apresentar-se como uma alternativa à "máinformação" do jovem, por ser feito em linguagem escrita e por tratar, diariamente, de temas considerados importantes para uma compreensão da realidade política, econômica e social em que esse jovem vive.

Por ser visto como porta-voz da informação, o jornal é "sacralizado", tanto em sua versão impressa como televisiva. A necessidade de manter-se informado tornou-se um dos requisitos na sociedade dita globalizada. Embora o telejornal ofereça um panorama dos principais acontecimentos do dia, será no jornal impresso que se poderá encontrar aquelas mesmas temáticas tratadas de forma mais densa, com um aprofundamento maior.

As seguintes perguntas são colocadas: Que representações sociais do jovem são mais freqüentemente encontradas nesse meio de comunicação, tido como importante fonte de informação diária? Existem cortes de classe nessas diferenças? Existem correlações entre o modo como a mídia representa o jovem e o modo como ele próprio se percebe e o grupo do qual faz parte?

\section{AS REPRESENTAÇÕES SOCIAIS}

Antes de trazer mais elementos sobre o trabalho, acredito que caibam algumas pinceladas sobre o conceito de representação social que foi tomado como guia. Vale a pena deixar claro que embora existam outras linhas de estudo sobre as representações, como as defendidas pela socioloia ou psicologia, os pressupostos adotados nesse trabalho falam de um lugar muito específico: o traçado por um olhar sociológico à psicologia social (Farr:1995:31). Assim, o conceito de representação social que trabalharei foi criado por Moscovici em 1961, partindo da necessidade que esse encontrou de aprofundar o conceito de representações coletivas construído por Durkheim, que tomava como ponto de partida explicativo a relação dos indivíduos com a religião, com o sagrado, que por serem baseados em verdades externas à percepção dos indivíduos e por não terem origem individual, apresentar-se-iam como relativamente fixos, pressionando os indivíduos a aceitalas. A representação seria aceita de forma homogênea, a ser vivida por todos os membros de um grupo, da mesma forma que partilham uma língua, como forma de preservar o vínculo entre eles e instaurar o pensamento uniforme. A representação seria coletiva porque perdura pelas gerações, exercendo coerção.

Embora Moscovici reconheça a força que o conceito de representações coletivas traz como forma de problematizar o individualismo nas análises sociais, esse autor cria o conceito de representações sociais, por acreditar que nesse termo caibam maior mobilidade e flexibilidade. O que passa a ser levado em conta são as construções contextualizadas de sujeitos sociais a respeito de objetos socialmente valorizados, que podem ser identificados através dos saberes populares e do senso comum, que seria criado por grupos como forma de explicação da realidade. Segundo Moscovici, as representações sociais se constituem como uma série de

\footnotetext{
${ }^{2}$ Barbero, Martin e Rey, German. Os exercícios do ver. Hegemonia audiovisual e ficção televisiva. São Paulo: Ed. SENAC São Paulo, 2001.
} 
opiniões, explicações e afirmações que são produzidas a partir do cotidiano dos grupos através das comunicações em geral, onde se elaboram os conhecimentos do senso comum. Sendo o jornal um meio de comunicação, que conhecimentos sobre a juventude esse veículo estará trazendo para a formação do ideário da sociedade sobre a juventude e para a formação de identidade desse grupo?

\section{A ANÁLISE DO JORNAL: PASSOS METODOLÓGICOS}

A metodologia para análise de mídia impressa já havia sido desenvolvida pelo Diretório de Pesquisa (CNPq) do qual faço parte: "Campos de problematização moral dos jovens e a influência da mídia", coordenado pela professora Apparecida Mamede, vinculado ao Departamento de Educação da PUC-Rio. Durante a pesquisa agora em fechamento, tivemos como tarefa analisar a maneira como diferentes temas - desemprego, violência, drogas, estética, entre outros, (citados por universitários como sendo os principais valores e problemas da juventude) ganhavam espaço nos jornais. Apropriando-me dos avanços alcançados pela pesquisa na construção dessa metodologia, parti para a análise dos jornais tendo dessa vez, como foco, a tematização da juventude.

A leitura do jornal para a minha pesquisa foi feita, então, tendo como objetivo inicial selecionar todas as matérias que trouxessem o tema juventude para suas páginas. Depois de recortadas, as matérias eram depositadas em diferentes sacos plásticos, pois me baseei na busca da triangulação temática observada primeiramente por Abramo: observar matérias COM, SOBRE e PARA jovens, tendo o cuidado de sempre anotar as referências das mesmas (em qual editoria, data e página foram publicadas).

Num segundo momento as matérias foram organizadas em uma planilha de forma de facilitar a análise posterior dos dados. Levando em consideração as observações feitas por Carmen Lozza ${ }^{3}$, as fotos, infográficos e ilustrações, além do tamanho das matérias, não podem ser esquecidos como constituintes da estrutura do jornal, devendo ser levados em conta quando estamos realizando uma revisão crítica.

Dessa maneira, a seguinte tabela foi construída:

\begin{tabular}{|l|l|l|l|l|l|l|l|l|l|}
\hline Editoria & Manchete & Tamanho & Foto & $\begin{array}{l}\text { Tam. } \\
\text { Foto }\end{array}$ & Cor & Famoso & Box & Quem & Fonte \\
\hline & & & & & & & & & \\
\hline
\end{tabular}

A escolha por esses campos teve por objetivo nortear minha análise: quais editorias são mais recorrentes no trato ao tema juventude? Há diferenças quando os jovens aparecem na editoria Capa ou no Segundo Caderno? As matérias são acompanhadas de fotos? Fotos de quem? Fotos de artistas são predominantes? Quais temas ganham boxes?

As planilhas eletrônicas se mostram muito úteis para o processo de análise, pois nos permitem criar gráficos e organizar tabelas a partir dos campos que nos interessarem. Por exemplo, posso abrir um arquivo que esteja ordenado pelo tamanho das matérias em ordem crescente (que tipos de matérias mereceram espaço grande?), um outro pelo tamanho da foto e ainda um outro para as que trouxeram fotos de artistas. Que representações sociais de juventude estão sendo transmitidas pelo jornal em questão?

\footnotetext{
${ }^{3}$ LOZZA, Carmen. Curso “Jornal: uma revisão crítica”, realizado no Paço Imperial, 2003.
} 


\section{APRESENTAÇÃO DE ALGUNS RESULTADOS}

Das 144 matérias que traziam a juventude como tema para as páginas do jornal, 56\% estavam COM; 33\% SOBRE e 11\% PARA jovens. Análises qualitativas nos permitirão mostrar que jovens são esses que aparecem, sobre o que falam a respeito deles e que temas são entendidos como sendo de interesse para eles.

Um outro ponto importante a ser observado é a forma como as editorias são privilegiadas para tratarem da tematização da juventude. A seguinte distribuição foi encontrada:

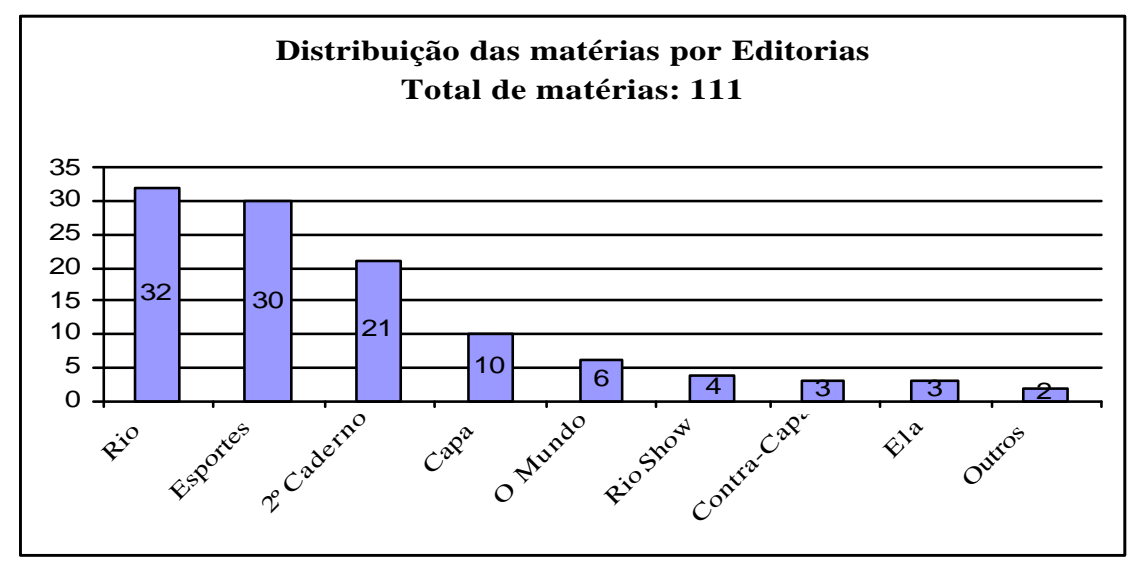

A forte incidência de jovens no caderno de Esportes ocorreu devido às proximidades das Olimpíadas em Atenas. Pode-se inclusive falar na "jovem", pois a maior parte das matérias $(45,1 \%)$ dizia respeito à ginasta Daiane dos Santos, de 19 anos, tida como grande esperança de vitória e conquista da quinta medalha de ouro, dessa vez com a coreografia "Brasileirinho". Matérias grandes, com fotos e acompanhamentos diários foram publicadas sobre o rendimento da ginasta.

Já nas outras editorias, os espaços foram preenchidos de forma dicotômica: de um lado atores/atrizes, modelos, jogadores de futebol e jovens ligados a bandas famosas e de outro, jovens envolvidos em atitudes violentas, brigas em festas, pancadarias. Se "estar na mídia" aparece como condição sine qua non para continuar nela, desenhando uma espiral sem fim, deve-se atentar para o fato que tematizar a juventude somente a partir de categorias profissionais que recebem acento da mídia soa no mínimo reducionista, devendo significar um sinal de alerta aos educadores e famílias. Por que só recebem visibilidade os jovens que trabalham em novelas e programas de televisão? Pelo o que pareceu na leitura dos jornais, a única maneira de um jovem receber espaço nas suas páginas, se não estiver em destaque na mídia, será através de notícias negativas, escândalos, brigas. Onde estão os jovens atuantes, ligados às artes, às letras, aos movimentos sociais, às produções culturais e políticas? Eles não existem? Ou estão sendo silenciados?

Entre matérias seguidas com poses de atrizes e modelos em festas, apenas uma nota trouxe luz, mesmo que fraca, no movimento estudantil. Não foi, ainda assim, uma matéria completa, mas uma nota na coluna do Ancelmo Góis, que embora tenha destaque, não traz aprofundamentos. Dizia:

"A UNE também decidiu cobrar mudanças na economia. Prepara protestos em diversas capitais. Uma caravana sai de Porto Alegre, dia 2, para pregar, pelo país, reformas econômica e universitária(...) Alguns atos começam antes. Hoje, tem manifestação em BH. Amanhã, em SP e BSB. Quinta será no Rio."

Segundo Caderno, 30/03/2004, p.16 
Por ser tratar de uma organização interestadual para protestos promovida pela UNE, não deveria o jornal ter se ocupado da divulgação das propostas com maior antecedência e esclarecimentos? Além da nota, nenhuma outra menção ao movimento recebeu linhas no jornal desse dia, nem para esclarecer o que seriam as reformas econômicas e universitárias propostas. No dia seguinte foi publicada uma notícia mais detalhada:

UNE volta às ruas por mudanças no ensino. Cerca de 2 mil estudantes participaram de uma passeata pelas ruas do centro de Minas. Reinvidicam 50\% das vagas nas universidades para estudantes da rede pública, a regulamentação do ensino superior privado, passe livre e garantia de financiamento para as universidades públicas.

O País, 31/03/2004, p.11

Caras pintadas (cerca de mil) retornam às ruas para lembrar os 40 anos do golpe de 64, em passeata convocada pela UNE e união dos secudaristas. 2/04/2004

Embora se possa ter a impressão do jornal ter dado atenção - mesmo que mínima- a jovens ligados ao movimento estudantil, quando comparamos a inserção dos outros grupos de jovens no jornal percebemos a dimensão da diferença. Observe como foram distribuídas as 111 matérias com jovens:

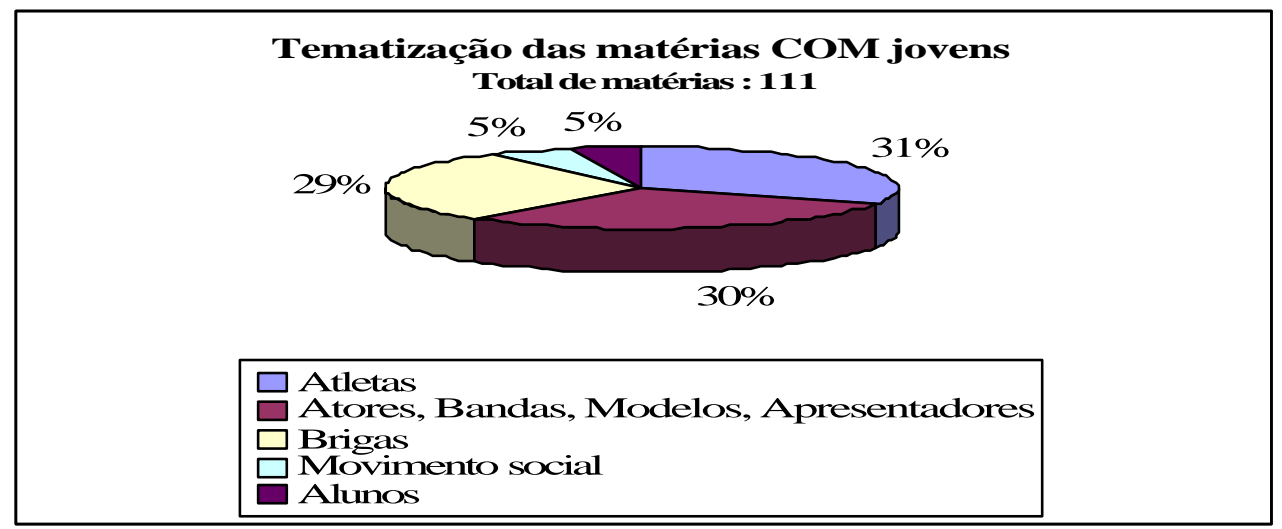

Levando em consideração que no grupamento "atletas" foram incluídas as inúmeras notícias com a ginasta Daiane dos Santos e toda a preparação para as Olimpíadas - além dos já tradicionais jogadores de futebol, a tematização da juventude está sendo feita, no jornal em questão, de forma desproporcional. Ao lado de jovens que se envolvem em brigas e adotam práticas violentas nas noites da Zona Sul carioca, atores, bandas, modelos e apresentadores de televisão (moradores do eixo Rio-São Paulo) recebem a maior fatia da exposição nos jornais, transformando esse veículo midiático numa vitrine invertida: práticas sociais, científicas, culturais e artísticas protagonizadas por jovens de diferentes lugares do Brasil não ressoam nas páginas do jornal.

No caso de matérias sobre os jovens, as Cartas dos Leitores dispararam devido à problemática envolvendo pitboys que ocorreram no período. A grande quantidade de cartas publicadas sobre $\mathrm{o}$ assunto reforçou a tônica da indignação contra atitudes violentas em jovens das camadas médias e altas da sociedade. A carta publicada em 5/04/2004 (p.6):

"Fica difícil pensar que a humanidade vai melhorar. Jovens agridem e são agredidos, são presos e liberados com a ajuda de advogados. A educação está errada, valores morais não existem. O soco na boca da sociedade é reforçado com a atitude do judiciário, de permitir a saída desses marginais que usam perfume francês. Isto só demonstra que estamos perdidos. Não haverá punição enquanto não houver uma tragédia." 
Total: $\mathbf{4 7}$ matérias

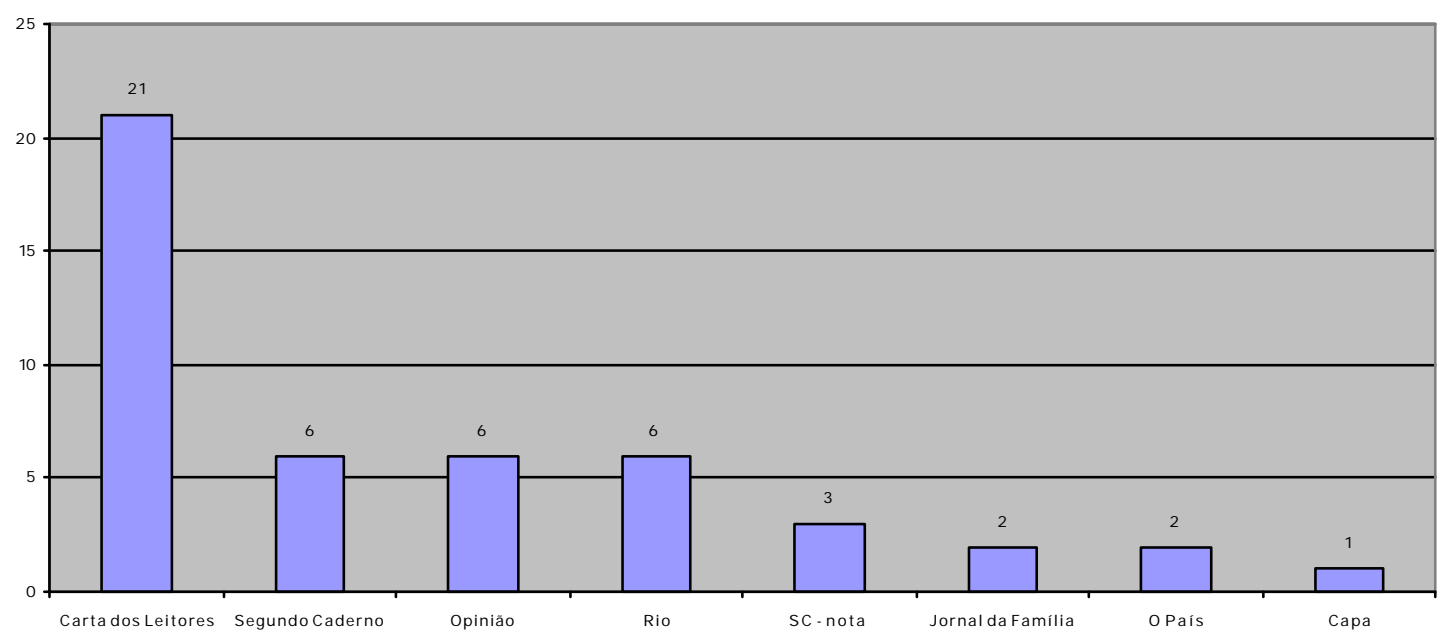

№ de matérias PARA jovens por EDITORIA Total: 16 matérias

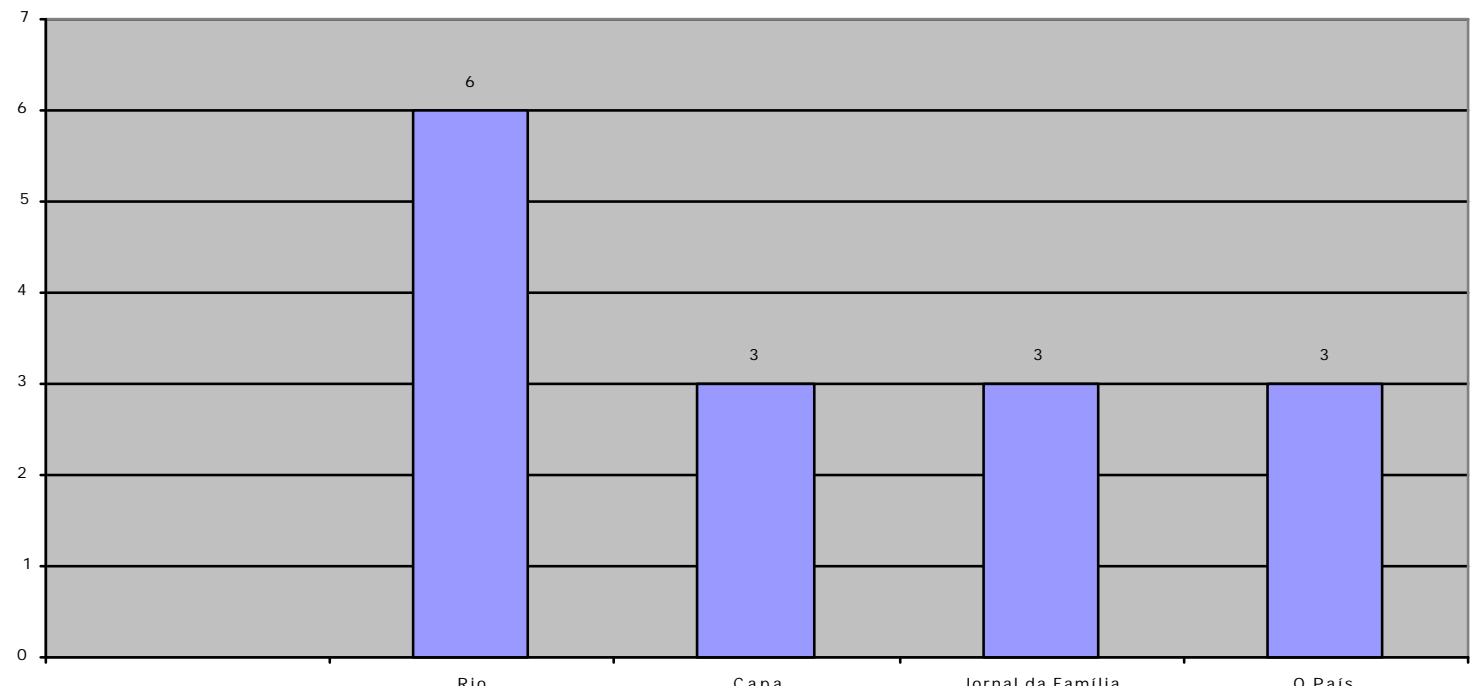

Por mais que o jornal em questão tenha uma publicação semanal destinada ao público jovem "Megazine", nesse estudo foram entendidas como matérias para os jovens as que eram apresentadas dentro da estrutura diária do jornal e não em cadernos específicos.

Foram encontradas matérias sobre diferentes temas, oscilando entre educação, lazer, esportes e entretenimento. Em compensação, a matéria que anuncia o término do FIES para que seja substituído pelo projeto Universidade para Todos (4/03/2004, p.9) perde a oportunidade de trazer discussões, debates e informações sobre a mudança. Já uma matéria sobre o Programa de Planejamento da Secretaria Municipal de Saúde, implantado em 1992, traz informações mais completas, principalmente por divulgar os telefones dos postos onde podem ser encontrados os serviços anunciados: 
Programa de Planejamento Familiar da Secretaria municipal de Saúde, implantado em 1992. Orienta-se sobre DSTs, contraceptivos, acesso a preservativos, indicação de ligadura de trompa, em reuniões de até 2 vezes por semana. Cerca de 25\% das mulheres que têm filhos no município do Rio tem menos de 20 anos. E a maioria completou apenas o ensino fundamental. Quase $30 \%$ dos partos do Hospital são de adolescentes. Dos 60 mil partos feitos anualmente, cerca de mil são de gestantes menores de 15 anos.

(Jornal da Família, 28 de março de 2004)

\section{CONSIDERAÇÕES}

Muitas reflexões podem ser feitas a partir da análise das matérias, mas o mais importante é o registro desse movimento de leitura atenta e crítica que nós, educadores, devemos manter continuamente. A formação dos alunos tem-se dado pela mídia de maneira informal e extra-escolar, se os professores não trouxerem a mídia para dentro da sala de aula, estarão perdendo uma oportunidade valiosa de diálogo capaz de aguçar o pensamento crítico dos alunos. Auxilia-los na reflexão sobre as imagens de si próprios veiculadas pela mídia contribui para o desenvolvimento de sujeitos ativos e mais conscientes. Até quando apenas atores, atrizes, jogadores de futebol e modelos continuarão nas pautas dos jornais, gerando um instantâneo fotográfico sobre os rostos da juventude brasileira?

Seleciono, pois, para finalizar, um trecho de entrevista concedida por Roger Silverstone ${ }^{4}$ para a $4^{\circ}$ Cúpula de Mídia 2004, no Rio de Janeiro:

"Uma coisa é certa: a mídia exerce tamanha influencia no nosso dia-a-dia que necessitamos de instrumentos de análise poderosos e sofisticados para avaliá-la. Acredito que devemos desenvolver estes instrumentos assim como novos princípios para a prática da educação para a mídia. Na minha avaliação, os jovens devem ser mais instruídos para lidar com o processo de representação da mídia. Capacitação que deveria fazer parte da educação básica, hoje e sempre."

\section{BIBLIOGRAFIA}

ABRAMO, Helena. Participação e organizações juvenis. Artigo publicado no Observatório bvem da UFF, em 13.07.2004. (www.uff.br/obsjovem)

Considerações sobre a tematização social da juventude no Brasil. in Juventude e Contemporaneidade, RBPE, nำ/6, ANPED, 1997.

CARRANO, Paulo Cesar Rodrigues. Os jovens e a cidade: identidades e práticas culturais em Angra de tantos reis e rainhas . Rio de Janeiro, Relume Dumará/Faperj, 2002.

Collaro, A. C. Projeto Gráfico: Teoria e prática da diagramação. São Paulo: Summus, 1987

DAUSTER, Tânia (org). A invenção do leitor [recurso eletrônico]: universitários, leitura e diferenças culturais. RJ: PUC-Rio, 2002.

DUARTE, Rosália. Cinema e educação. Belo Horizonte, Autêntica Editora, 2002

ERBOLATO, M. L Jornalismo Gráfico. São Paulo: Loyola, 1981

FARR, Robert. Representações sociais: a teoria e sua história. IN: Textos em representações sociais. Petrópolis, RJ: Vozes, 1995, p.31-59. 
GUARESCH, P e JoVCHeLOVITCH, S. (orgs) Textos em representações sociais. Petrópolis, RJ: Vozes, 1995.

JODELET, D (org). Representações sociais. RJ; Eduerj, 2002.

MAMEDE-NEVES e outros Campos de problematização moral do jovem e a influência da mídia, Rio de Janeiro: PUC-Rio, 2002 Projeto de pesquisa apoiado pelo CNPq.

MAMEDE-NEVES, M.A. C. A construção do juízo moral em grupos de jovens pertencentes a "sociedades emergentes"- um estudo na Barra da Tijuca, Rio de Janeiro. Rio de Janeiro. PUC-Rio, 2001. (relatório final do Projeto Integrado CNPq)

MoscoviCl, Serge. Das representações coletivas às representações sociais: elementos para uma história. IN: JODELET, D. (org) Representações sociais. RJ: Eduerj, 2002, p.45-66.

OLTRAMARI, Leandro Castro. Artigo publicado na internet: www.cfh.ufsc.Br/ dich/TextoCaderno45.pdf. Data do acesso: 06/10/2004.

Peralva, Angelina. O jovem como modelo cultural. in Juventude e Contemporaneidade, RBPE, n5ㄴ 6 , ANPED, 1997.

RABAÇA, C. A. e BARBOSA, G. Dicionário de Comunicação. Rio de Janeiro: 1978

RIVOLTELLA, Píer Cesare. Media Education: modelli, esperienze, profilo disciplinare.

Roma:Carocci, 2001.

SILVA, R. S. Diagramação - o planejamento visual gráfico na comunicação impressa. São Paulo: Summus, 1985

SILVERSTONE, Roger. Por que estudar a mídia? RJ: Ed. Loyola, 2002.

SODRÉ, M. A comunicação do grotesco - um ensaio sobre a cultura de massa no Brasil. Petrópolis (RJ): Vozes, 1985

SPOSITO, Marília Pontes. Os jovens no Brasil: desigualdades multiplicadas e novas demandas políticas. SP: Ação Educativa, 2003.

\footnotetext{
${ }^{4}$ Entrevista disponível no site http://www.riosummit2004.com.br/Noticias_full.asp?Id_noticias=1963\&ldioma=por
} 


\title{
Contactar
}

Revista lberoamericana de Educación

\author{
Principal OEI
}

